\title{
HILGARDIA
}

A Journal of Agricultural Science Published by the California Agricultural Experiment Station

\section{EFFECT OF OIL SPRAY ON CALIFORNIA RED SCALE AT VARIOUS STAGES OF DEVELOPMENT}

WALTER EBELING 


\title{
$\begin{array}{lllllllll}H & \text { I } & \text { L } & G & A & R & D & \text { I } & \text { A }\end{array}$
}

A Journal of Agricultural Science Published by

the California Agricultural Experiment Station

VOL. 10

APRIL, 1936

No. 4

\section{EFFECT OF OIL SPRAY ON CALIFORNIA RED SCALE AT VARIOUS STAGES OF DEVELOPMENT ${ }^{1,2}$}

\author{
WALTER EBELING ${ }^{3}$
}

\section{INTRODUCTION}

DURING SEVERAL YEARS of field investigation with oil sprays used against the California red scale, Aonidiella aurantii (Mask.), the writer has observed that often some insects may not have received a sufficient amount of oil to cause sudden death and that they may live for two or three weeks after other individuals have been killed. Where the lethal action is thus prolonged, the typical signs of death, such as dryness or discoloration of the body fluids, may not be definitely discernible until six weeks or more after the spray treatment. In many cases examinations of infested citrus groves a month after treatment with oil spray have revealed an unsatisfactory degree of control of the red scale; at the end of six weeks, however, the mortality of the insects was very much higher.

The work of deOng, Knight, and Chamberlin (1927, p. 372) indicated that the lethal effect of highly refined oil sprays is the result of suffocation of the insect, but Smith (1932) has observed that often the oil does not reach the tracheae, and in that case death may be caused by a "prolonged impairment of physiological processes such as might be induced by the presence of oil in the scale covering or in contact with the derm of the insect's body." In cases in which the lethal effect is retarded because of incomplete suffocation, the appearance of the insect indicates that it has some oil in its body. Its scale covering is oily, and a certain amount of dust has adhered to the oil film.

Another factor enhancing the effectiveness of oil sprays beyond their

${ }^{1}$ Received for publication December 5, 1935.

${ }^{2}$ Paper No. 333, University of California Citrus Experiment Station and Graduate School of Tropical Agriculture, Riverside, California.

${ }^{3}$ Junior Entomologist in the Citrus Experiment Station. 
initial lethal capacity is believed to be the inhibition of the settling of the scale crawlers ${ }^{4}$ for a period after the application of an oil spray and the high rate of mortality among those which are able to settle. Woglum (1926) states that the residual oil prevents the settling of crawlers "for a considerable period" on the fruit and new wood, and Woglum and La Follette (1934) more recently conclude that the inhibition of the settling of the young insects in this manner is "one of the most important considerations in red-scale control by oil spray." Since the mortality resulting from oil sprays is known to be sometimes very low, especially on lemon trees and on rough bark (Ebeling, 1932), the inhibition of the settling of the crawlers born of the insects surviving the spray treatment may be a salient factor to consider in an appraisal of the ultimate efficiency of oil sprays.

Other factors, aside from the obvious factor of tracheal penetration, that might influence the effectiveness of an oil spray treatment, such as suffocation caused by sealing of the edges of the scale by the oil, penetration of oil through the derm of the insect, and the effect of oil on reproductivity, were deemed worthy of experimental investigation in order that a more complete understanding might be obtained concerning the nature of the reaction of red scale to oil spray. This knowledge, in turn, might serve as a basis for experimentation on control measures. In order that the work might be systematically pursued, the reaction of each life stage of the red scale to oil spray was considered separately.

\section{INHIBITION OF THE SETTLING OF CRAWLERS}

Experiments were made to determine to what extent the settling of redscale crawlers is inhibited by oils of various degrees of heaviness and sprays at different concentrations. On October 16, 1932, two leaves of an orange seedling were treated with a grade- 4 (medium) ${ }^{5}$ oil applied at 2 per cent concentration as a tank-mixture spray (Smith, 1933) by means of a quart-capacity hand sprayer; the remainder of the seedling was left untreated. On October 17, 20 red-scale crawlers were placed on each of 2 sprayed and 2 unsprayed leaves. A camel's-hair brush was used to transfer the crawlers. The petioles of the leaves were banded with tanglefoot so as to keep the transferred crawlers from leaving the leaf. Two days later the leaves were examined so that the whitecaps, ${ }^{\circ}$ if any, could be counted and removed; 20 more crawlers were then placed

"Crawlers" are the newly born young of the red scale; they move about for a period of several hours to two days, after which they settle on the host and, in the case of the females, remain sessile throughout their lives.

${ }^{5}$ Distillation range: 10 per cent at $592^{\circ} \mathrm{F}$ and 90 per cent at $722^{\circ} \mathrm{F}$.

- After the crawlers have settled, they secrete a white, waxy substance which covers their bodies and gives them the common designation "whitecaps." 
on each leaf. This process was repeated every two days until December 10. The seedling was kept in a laboratory at a mean temperature of $65^{\circ} \mathrm{F}$.

No whitecaps occurred on the sprayed leaves until November 2,16 days after the application of the spray. On that date 1 whitecap was found on leaf A. On leaf B, no whitecap appeared until November 16,

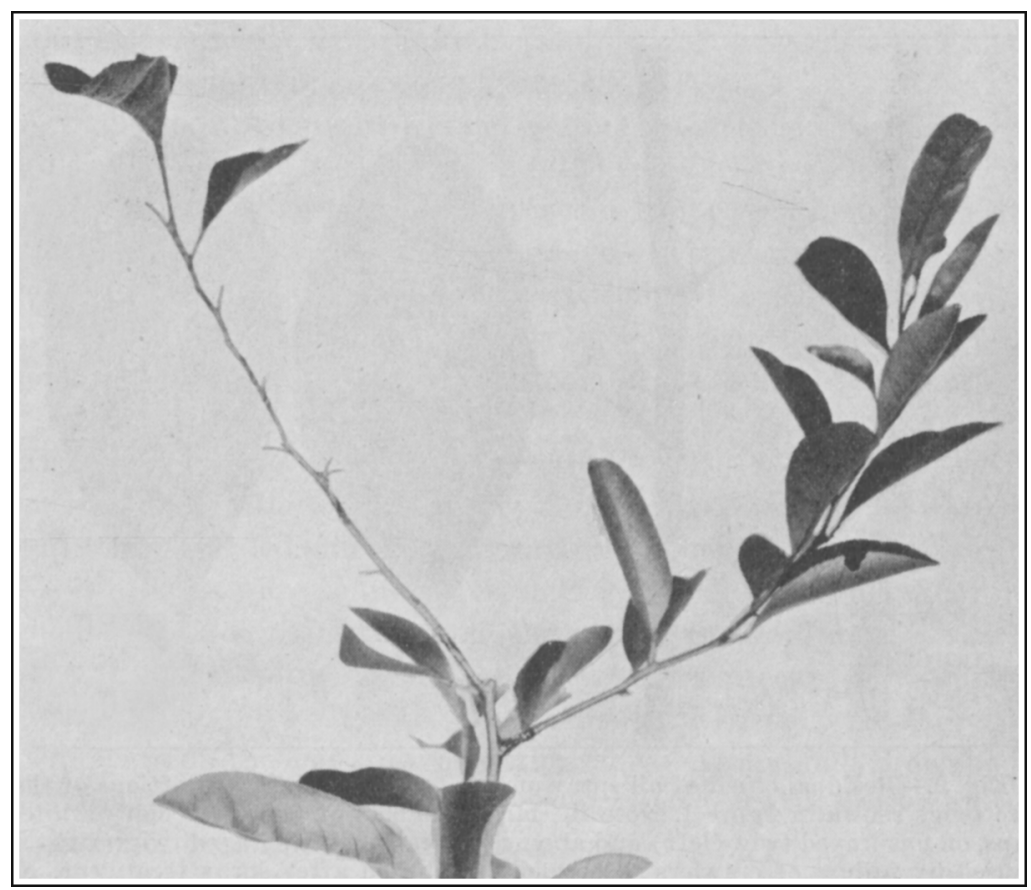

Fig. 1.-Residual effect of oil sprays on two twigs of an orange seedling. Left, twig untreated; right, twig sprayed with 2 per cent grade-4 (medium) oil. Over a period of 53 days after treatment, 400 red-scale crawlers were placed on each twig. Note defoliation of unsprayed twig.

30 days after the application of the spray. The reason for the great difference in the dates of the first appearance of crawlers on the two sprayed leaves is not apparent, unless it can be accounted for by unintentional variation in the application of the spray, resulting in a greater deposit of oil on leaf B. Only 3 whitecaps had appeared on leaf A, however, before the first whitecap appeared on leaf B. After November 16 the number of crawlers able to settle on the sprayed leaves gradually increased until on December 8, 11 settled on leaf A and 9 on leaf B. During all of this time the number settling on the unsprayed leaves varied between 5 and 17 with an average of 10 per observation on each leaf. 
In another experiment two twigs of a lemon seedling were progressively infested with red-scale crawlers. One of the twigs had been sprayed with 2 per cent medium oil and one had been left untreated as a check. Twenty crawlers were transferred to each twig every second day for 40 days. The sprayed twig was isolated by a band of tanglefoot. The spraying was done on October 26 , and on December 3 the first white-

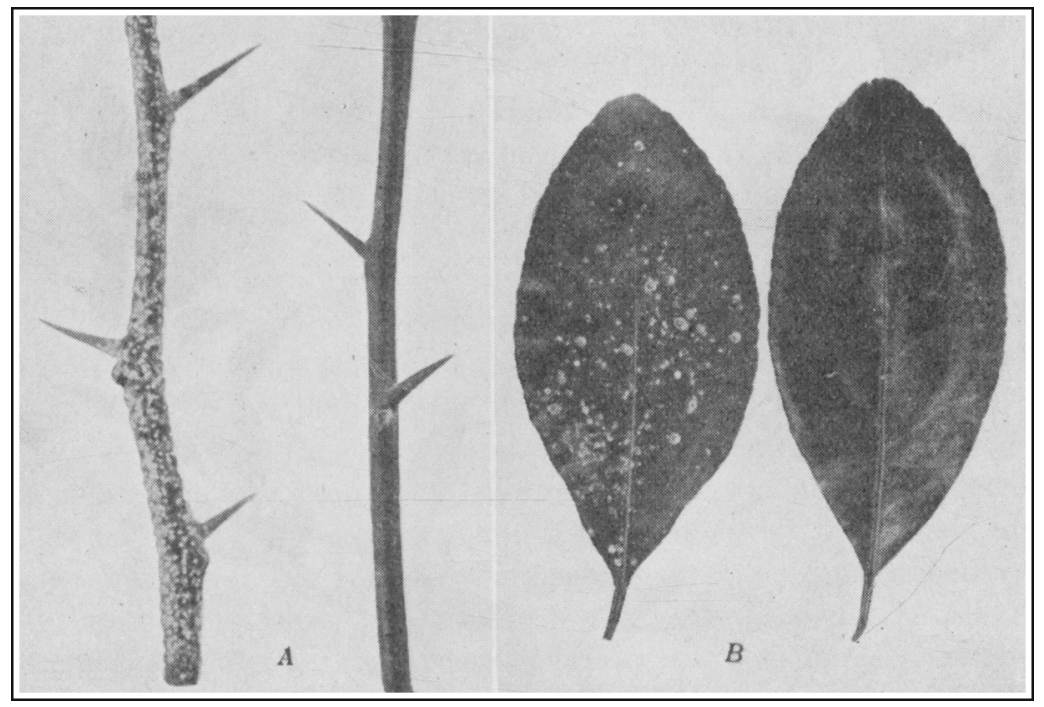

Fig. 2.-Residual effect of oil spray on an orange seedling. $A$, Portions of the two twigs shown in figure 1 . Note the large numbers of scale, especially whitecaps, on unsprayed twig (left) and absence of scale on the sprayed twig (right), caused by failure of crawlers to become established after spray treatment. $B$, Leaf taken from unsprayed twig (left) and leaf taken from sprayed twig (right) of orange seedling shown in figure 1 . Note absence of scale on sprayed leaf.

cap was found on the twig which had been treated. Thus 39 days had elapsed before a single crawler was able to settle on the sprayed twig.

Figures 1 and 2 are photographs which were taken on January 26, 1933, three months after the first crawlers had been transferred to the lemon seedling. On 1 inch of the unsprayed twig 3 mature females, 6 males, and 112 whitecaps were counted. The sprayed twig was entirely free of insects, the one crawler that settled on December 3 having died. The large number of whitecaps and of red scales in other stages on the unsprayed leaf (fig. 2, B) illustrates the rapidity with which a dense population of red scale is built up; it also indicates that the inhibition of the settling of crawlers may be a potent factor in minimizing the seasonal population of the red scale.

Effect of Heaviness of Oil.--Having experimentally established the 
fact that the presence of oil on the surface of the citrus tree inhibits the settling and subsequent development of the crawlers, it was considered desirable to determine the differences in the inhibitory effects of sprays composed of oils of different degrees of heaviness. The sprays were tank mixtures and included two grades of spray oil : grade-5 (heavy) oil, ${ }^{7}$ used commercially only in the spraying of lemon trees; and a grade known commercially as Oronite Crystal, ${ }^{8}$ which is heavier than any oil used in citrus spraying.

A vigorous two-year-old orange seedling was selected for the purpose of this experiment. On December 20,1932, one leaf was sprayed with 2 per cent Oronite Crystal oil, an adjacent leaf was sprayed with 2 per cent grade-5 (heavy) oil, and a third leaf was left untreated as a check. The spray was applied, as in previous experiments, with a quart-capacity hand sprayer. The petioles of the leaves were banded with tanglefoot. The tree was left in a well-lighted room at a constant temperature of $80^{\circ} \mathrm{F}$.

From December 29, 1932, to February 28, 1933, 25 red-scale crawlers were transferred to each leaf every 2 days; the numbers of whitecaps found were recorded and the whitecaps were then removed.

No whitecaps were found on the leaf sprayed with grade-5 oil until January 20, 1933, 31 days after the spray was applied. On the leaf sprayed with Oronite Crystal oil, the first whitecap was found on January 26, 36 days after the treatment. By February 28, there were 14 whitecaps on the leaf sprayed with grade-5 oil, and only 1 on the leaf sprayed with Oronite Crystal oil ; 333, or an average of 15.13 whitecaps per day, had been found on the check leaf.

Effect of Oil on Whitecaps.-A condition that would so profoundly affect the settling and development of the crawlers might be expected to affect also the future development of those individuals which are able to settle and reach the whitecap stage. Experiments were made to determine to what extent, if any, the presence of oil on citrus foliage would hinder the development of whitecaps.

On March 20, 1933, red-scale crawlers were placed on each of the leaves referred to above. Ninety days after the leaves had been treated, 100 crawlers were placed on the leaf sprayed with Oronite Crystal oil (leaf A), 300 on the leaf sprayed with grade-5 (heavy) oil (leaf B), and 100 on the check leaf (leaf C). Two days later 1 whitecap was found on leaf A, 31 on leaf B, and 70 on leaf C. On April 6 the leaves were examined again to determine the percentage of whitecaps which had survived on the three leaves. The single whitecap on leaf A had died, 16 had

\footnotetext{
${ }^{7}$ Distillation range: 10 per cent at $612^{\circ} \mathrm{F}$ and 90 per cent at $737^{\circ} \mathrm{F}$.

${ }^{8}$ Distillation range not known; viseosity 120 seconds Saybolt.
} 
survived on leaf $\mathrm{B}$, and 58 had survived on leaf $\mathrm{C}$. The percentage of survival, therefore, was as follows : leaf A, 0.00 per cent; leaf B, 51.61 per cent; and leaf C, 82.83 per cent. On another leaf, treated on January 7 with a spray containing grade- 5 oil at 2 per cent concentration, and upon which 300 crawlers had been placed on March 20, 5 whitecaps out of 17 survived, making a survival of 29.41 per cent.

Experiments Made under Commercial Conditions.-Observations made in groves which had been sprayed for red scale indicated that the

TABLE 1

Number of Red-Scale Whitecaps Forming on SPRAyed and UNTreated ORANGE TWIGS*

\begin{tabular}{c|c|c|c}
\hline \hline \multirow{2}{*}{ Treatment } & \multicolumn{2}{|c|}{ Number of whitecaps } & $\begin{array}{c}\text { Crawlers } \\
\text { developing into } \\
\text { whitecaps, } \\
\text { per cent }\end{array}$ \\
\cline { 2 - 4 } & Leaf A & Leaf B & \\
\hline
\end{tabular}

Fifty crawlers transferred March 3, 1933

\begin{tabular}{|c|c|c|c|}
\hline Grade 4 oil (medium) $12 / 3$ per cent $\ldots \ldots \ldots \ldots \ldots \ldots \ldots$ & 1 & 8 & 9 \\
\hline 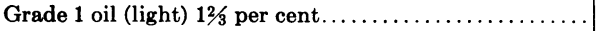 & 19 & 23 & 42 \\
\hline 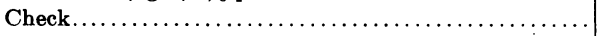 & 32 & 36 & 68 \\
\hline
\end{tabular}

Fifty crawlers transferred March 10, 1933

\begin{tabular}{|c|c|c|c|}
\hline Grade 4 oil (medium) $12 / 3$ per cent $\ldots \ldots \ldots \ldots \ldots \ldots \ldots$ & 14 & 10 & 24 \\
\hline Grade 1 oil (light) $12 / 3$ per cent. $\ldots \ldots \ldots \ldots \ldots \ldots \ldots$ & 23 & 27 & 50 \\
\hline 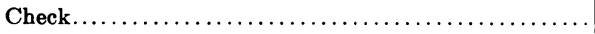 & 31 & 39 & 70 \\
\hline
\end{tabular}

* Sprayed by means of a power sprayer, Feb. 10, 1933.

period of inhibition of the settling of crawlers caused by the presence of oil spray on the foliage was shorter in commercially sprayed trees than on the seedlings which had been experimented with in the laboratory. This was probably caused mainly by the difference in the nature of the spray deposit between foliage sprayed with a power sprayer and that sprayed with a hand sprayer. Although the foliage of the seedlings treated in the laboratory did not receive sufficient oil to cause any appreciable signs of injury, such as dropping of the leaves, it had probably received a heavier deposit of oil than if the spray had been applied with a power sprayer. Furthermore, the dark green, vigorous leaves found on rapidly growing seedlings do not allow as rapid penetration of oil as the average leaves on mature orchard trees. Factors peculiar to outdoor conditions, such as direct sunlight and air movement, no doubt also had their effect in shortening the period of inhibition.

On February 10, 1933, a number of large Washington Navel orange trees were sprayed with $12 / 3$ per cent grade-4 (medium) oil and $1 \% 3$ per 
cent grade-1 (light) oil with spray prepared by the tank-mixture method. The spray was applied with a power sprayer, No. 7 disks being used in the nozzles; a pressure of 400 pounds was employed. On March 3, twigs were taken from trees sprayed with the two grades of oil, as well as from a check tree, and were placed in jars of water in a room at $80^{\circ} \mathrm{F}$ constant temperature. Two leaves from each twig were selected, to which were transferred red-scale crawlers from heavily infested lemons. Fifty

TABLE 2

The Effect of Oil Spray in Inhibiting the Settling of Red-Scale Crawlers AND THE DeVelopment OF Whitecafs*

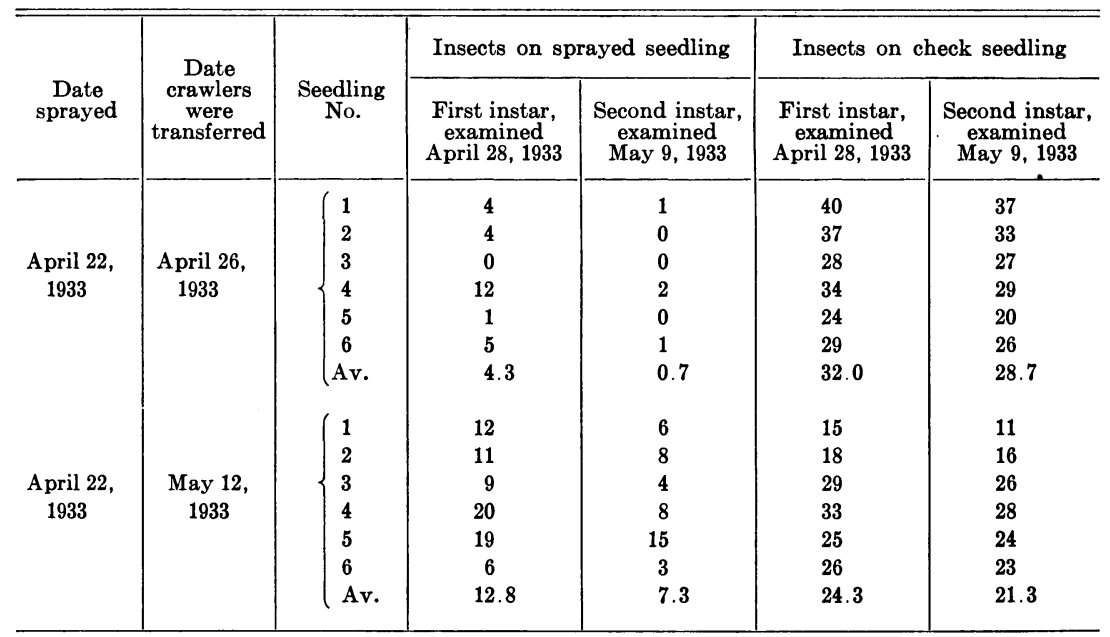

* Sprayed by means of a power sprayer.

crawlers were placed on each leaf, and the petioles of the leaves were banded with tanglefoot. Transfers were made in a similar manner on March 10. The results of the experiment are shown in table 1.

Of the crawlers transferred to the sprayed leaf on March 3, 21 days after the spray treatment, only 9 per cent formed whitecaps on the two leaves sprayed with $12 / 3$ per cent mediurn oil as compared with 68 per cent on the two check leaves. Seven days later the percentage on the sprayed leaves had increased to 24 . This, however, indicates a marked inhibition of the settling of crawlers even a month after the spray is applied. If the crawlers had been transferred outdoors instead of in the laboratory, the percentage forming whitecaps would have been very small, and comparisons between treatments would have been less significant.

On April 22, 1933, 6 orange seedlings were sprayed with a grade-5 (heavy) oil at $3 / 4$ of 1 per cent concentration, the equipment employed 
being the same as that of the previous experiment. The seedlings were placed in a room at $80^{\circ} \mathrm{F}$ constant temperature. Four days later one leaf was chosen from each of the sprayed seedlings and one from each of 6 seedlings left unsprayed as a check. Fifty crawlers were placed on each leaf. On April 28, counts were made of the number of whitecaps on the sprayed and check leaves, and on May 9 counts were made of the number of insects which continued development to the second instar. On May 12, a leaf on each of the seedlings sprayed April 22 and one on

TABLE 3

Effect of Grade-5 (Heavy) Oil in Inhibiting the Settrling and Development of Red SCALE under ORchard Conditions

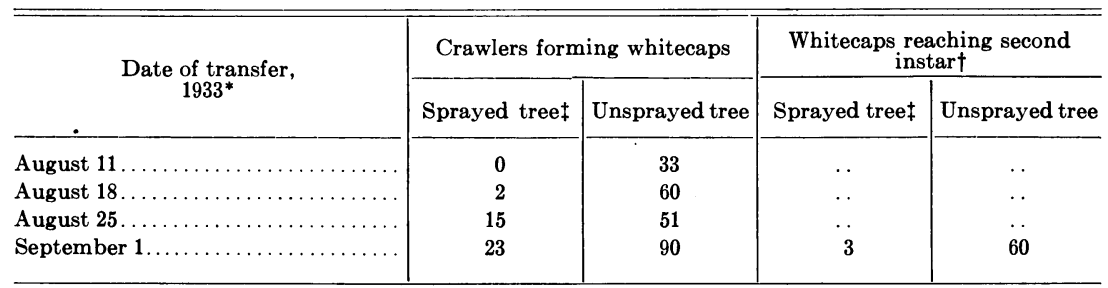

* A total of 200 crawlers transferred on each date to each tree, with 50 crawlers on each of four leaves. $\dagger$ Records kept only for crawlers transferred September 1 and forming whitecaps.

† Sprayed August 4, 1933.

each of the check seedlings was again chosen for infestation. Fifty crawlers were placed on each leaf, and observations were made as in the previous experiment. The data regarding the two experiments are presented in table 2.

Although only $3 / 4$ of 1 per cent grade- 5 oil was used in the spray mixture, only 8.6 per cent of the crawlers transferred to the seedlings 4 days after the spraying developed into whitecaps as compared with 64.0 per cent on the check seedlings. When the crawlers were transferred 20 days after spraying, 25.6 per cent developed into whitecaps as compared with 48.6 per cent on the check seedlings.

Observations on Crawlers Transferred under Orchard Conditions.The purpose of this experiment was to determine the behavior of crawlers transferred in the orchard, where the mortality is higher than in the laboratory, probably mainly because of low night temperatures. On August 4, 1933, a lemon tree was sprayed with grade-5 oil at 1\%3 per cent concentration and an adjacent tree was left unsprayed as a check. The $1 \frac{2}{3}$ per cent concentration is the usual dosage used for red scale on lemons. At intervals of one week, 50 red-scale crawlers were transferred from heavily infested lemons to each of 4 leaves on both the sprayed and check trees. Each time crawlers were placed on the leaves, those settling from previous transfers were removed. As in previous experiments, the 
petioles of the leaves were smeared with tanglefoot and the crawlers were transferred by means of a camel's-hair brush. The results of the experiment are given in table 3 .

Of the crawlers transferred to the sprayed leaves 28 days after the application of the spray 11.5 per cent formed whitecaps, but only $\mathbf{1 . 5}$ per cent survived to the second instar. On the check leaves 45.0 per cent formed whitecaps and 30.0 per cent survived to the second instar.

\section{TABLE 4}

Oiliness of Red-Scale Crawlers at Various Intervals after Treatment*

\begin{tabular}{|c|c|c|c|}
\hline Date, January, 1933 & $\begin{array}{l}\text { Number of } \\
\text { crawlers }\end{array}$ & $\begin{array}{l}\text { Number of } \\
\text { crawlers oily in } \\
\text { less than } \\
30 \text { seconds }\end{array}$ & $\begin{array}{l}\text { Number of } \\
\text { crawlers oily in } \\
\text { less than } \\
1 / 2 \text { hour }\end{array}$ \\
\hline 16.. & 20 & 20 & 20 \\
\hline $17 \ldots$ & 20 & 20 & 20 \\
\hline $18 \ldots \ldots \ldots$ & 20 & 20 & 20 \\
\hline $21 \ldots \ldots \ldots \ldots \ldots \ldots \ldots \ldots \ldots \ldots \ldots \ldots \ldots \ldots$ & 20 & 8 & 20 \\
\hline $22 \ldots \ldots \ldots \ldots \ldots \ldots \ldots \ldots \ldots \ldots \ldots \ldots \ldots$ & 10 & 3 & 10 \\
\hline $23 \ldots \ldots \ldots \ldots \ldots \ldots \ldots \ldots \ldots \ldots \ldots \ldots \ldots \ldots \ldots$ & 20 & 4 & 18 \\
\hline $25 \ldots \ldots \ldots \ldots \ldots \ldots \ldots \ldots \ldots \ldots \ldots \ldots \ldots \ldots$ & 20 & 4 & 11 \\
\hline $27 \ldots \ldots \ldots \ldots \ldots \ldots \ldots \ldots \ldots \ldots \ldots \ldots \ldots \ldots$ & 20 & 2 & 8 \\
\hline $30 \ldots \ldots \ldots \ldots \ldots \ldots \ldots \ldots \ldots \ldots \ldots \ldots \ldots$ & 10 & 0 & 0 \\
\hline
\end{tabular}

* The crawlers were placed on orange leaves sprayed with 2 per cent grade-5 (heavy) oil on January $15,1933$.

Behavior of Crawlers after Spray Treatment.-In an effort to determine the cause of the inability of crawlers to settle on oil-sprayed leaves, a potted lemon seedling was sprayed with 2 per cent grade-5 (heavy) oil. At various periods thereafter for two weeks, lots of 10 or 20 crawlers were transferred to certain leaves of the sprayed seedling, and the leaves were then removed for examination with a binocular. The results of the experiment are shown in table 4.

The crawlers placed on the seedling the first day after the latter was sprayed, were immediately mired in the oil on the surface of the leaf and could not move. They were soon covered with a film of oil. Those placed on the seedling during the next two days could move some distance with difficulty, but the margin of the body would often come in contact with the oil on the leaf surface, and because the waxy surface of the body of a crawler is wet so readily, a film of oil crept over the body of each insect, usually within 10 or 15 minutes. The creeping of oil over the body of a crawler may be watched with the aid of a binocular. The crawlers are yellowish and opaque when placed on the sprayed leaf. After moving about for some time they gradually become oily and translucent, and for the first day or two after the leaf is sprayed they may actually draw a pool of oil from the leaf surface about their bodies. 
Of the 20 crawlers placed on the seedling on the sixth day after spraying, only 8 were covered with an oil film from the leaf surface within 30 seconds, and the majority were able to crawl about for half an hour before becoming oily. Among those placed on the seedling on the eighth day, 4 out of 20 were affected in this manner within 30 seconds and 18 out of 20 before the end of a half-hour period. Among the crawlers placed on the seedling on the fifteenth day, none were appreciably covered with oil even after dying and having a large portion of their bodies in contact with the leaf surface. None, however, were able to form whitecaps. After the oil film had for the most part penetrated into the leaf, the crawlers would often live long enough to insert their beaks into the leaf, but would die before reaching the whitecap stage.

Comparative studies on the inhibition of the settling of red-scale crawlers were not made on the rough bark because of the great variability in the capacity of the bark to absorb oil and because of the very small percentage of crawlers able to settle even on the unsprayed bark. Owing to the fact that the oil film is less persistent on the bark than on the leaf surface, the settling of crawlers may be inhibited for a much shorter period.

Attempts at Control Directed against Crawlers.-The practicality of killing or inhibiting the development of crawlers by repeated spray treatments with small concentrations of oil is very remote. This is owing to the large number of applications necessary over perhaps a two-month period in order to effect a control. The frequency of application is made necessary by the rapid absorption of the oil by the bark, on which the crawlers are often very numerous.

Experiments were made to investigate the possibility of inhibiting the development of crawlers by the use of various dusts, such as lime, talc, diatomaceous earth, and sulfur, with or without a certain amount of oil or toxic substance mixed with the dust. In the laboratory citrus seedlings could be kept free from red-scale infestation by dusting them with sufficient quantities of an oil-impregnated or even an undiluted, inert dust. In these experiments thousands of red-scale crawlers were transferred to treated and untreated seedlings and the number settling. on the leaves and twigs was determined. A 100 per cent inhibition of settling was often obtained. Field experiments, however, showed the impracticability of this type of control on a commercial basis, because of the impossibility of applying dust in sufficient quantities on both sides of the leaves all through the trees and because of the large number of treatments necessary. 


\section{EFFECT OF OIL SPRAY ON IMMATURE STAGES}

Crawler Stage.-Since the crawler and whitecap stages are killed by even such small amounts of oil as are found on or in the leaves several weeks after spraying, obviously they must succumb to the oil actually sprayed upon them, even at the lowest concentrations used in citrus spraying.

\section{TABLE 5}

Difference in Survival of Adult and Immature Red Scale

\begin{tabular}{|c|c|c|c|c|c|c|}
\hline \multirow{2}{*}{ Life stages } & \multirow{2}{*}{$\begin{array}{c}\text { Per cent of } \\
\text { oil }\end{array}$} & \multicolumn{2}{|c|}{ Treated insects } & \multicolumn{2}{|c|}{ Check (untreated) insects } & \multirow{2}{*}{ Net mortality, ${ }_{\text {per cent }}^{*}$} \\
\hline & & Total & $\begin{array}{l}\text { Per cent } \\
\text { alive }\end{array}$ & Total & $\begin{array}{l}\text { Per cent } \\
\text { alive }\end{array}$ & \\
\hline Adults. & $\left\{\begin{array}{l}1 \\
2\end{array}\right.$ & $\begin{array}{l}1,776 \\
1,576\end{array}$ & $\begin{array}{l}25.9 \\
15.4\end{array}$ & $\begin{array}{l}1,437 \\
1,437\end{array}$ & $\begin{array}{l}84.4 \\
84.4\end{array}$ & $\begin{array}{l}69.3 \pm 0.80 \dagger \\
81.8 \pm 0.71\end{array}$ \\
\hline Immature stages $t$ & $\left\{\begin{array}{l}1 \\
2\end{array}\right.$ & $\begin{array}{l}1,861 \\
1,567\end{array}$ & $\begin{array}{l}3.6 \\
1.3\end{array}$ & $\begin{array}{l}1,472 \\
1,472\end{array}$ & $\begin{array}{l}84.6 \\
84.6\end{array}$ & $\begin{array}{l}95.7 \pm 0.34 \\
98.5 \pm 0.23\end{array}$ \\
\hline
\end{tabular}

* Calculated as $\frac{x-y}{x}$ when $x=$ percentage left alive in untreated lot and $y=$ percentage left alive in treated lot.

$\dagger$ Probable error computed from the formula P.E. $=0.6745 \sqrt{\frac{p q}{(n-d)}}$ when $p=$ net per cent mortality; $q=100-$ net per cent mortality; $n=$ number of insects counted; and $d=$ number of $n$ which would have died from natural causes during the course of the experiment as determined by the percentage of dead insects in the check. The P.E. is less reliable for extremely large values of $p$ or $q$, as with the data under "Immature stages" in this table, because deviation from the mean becomes less symmetrical as $p$ and $q$ vary from the condition in which $p=q=50$ per cent.

$\ddagger$ Immature stages include those from the first molt to and including the gray adult. Grade-5 (heavy) oil was sprayed January 14,1935 , and the insects examined February $1,1935$.

Other Immature Stages.-All other immature stages of the red scale (fig. 3) are likewise killed by far less oil than is necessary to kill the adults. Thus, a 1 per cent concentration of grade-5 (heavy) oil sprayed on the fruit, green twigs, or leaves of the lemon, or a 1 per cent concentration of grade-3 or 4 (light-medium or medium) oil on the fruit, green twigs, or leaves of the orange, is sufficient to kill nearly all immature stages of the red scale up to and including the "gray adult.", Some may be left alive, however, when the same amount of oil is sprayed on the bark.

To secure more data regarding the matter, lemons heavily infested with red scale were obtained, and the insects showing by their appearance that they were dead were removed. All fruits were then sprayed with grade- 5 oil at 1 per cent and 2 per cent concentrations by means of a laboratory precision sprayer. The fruit was kept in paraffin paper sacks in a room at a temperature of approximately $65^{\circ} \mathrm{F}$. Eighteen days after treatment the number of live adults and the number of live immature stages from the first molt to and including the gray adult were

\footnotetext{
${ }^{\circ} \mathrm{By}$ "gray adult" is meant the stage between the second molt and the mature adult.
} 


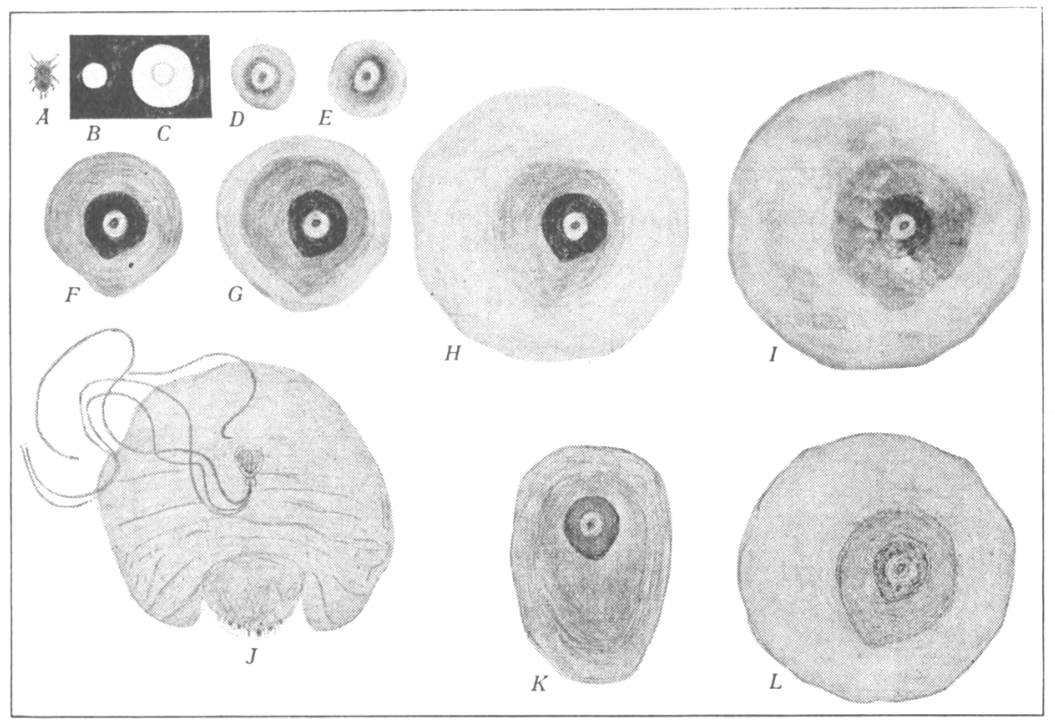

Fig. 3.-The development of the red scale as it appears on the plant. $A$ to $J$, Stages of the female scale: $A$, motile young or "crawler"; $B$, white cap; $C$, nipple stage ; $D$, first molt ; $E$, secretion of gray wax margin after first molt; $F$, second molt; $G$, secretion of gray wax margin after second molt; $H$, completion of extension of scale covering by enlargement of gray wax margin. This stage may be called the gray adult. $I$, The adult or young-producing stage.

The first cast skin is incorporated in the scale covering, as shown by the darker inner circles in $F, G, H$, and $I$. The second cast skin is represented by the outer margin in $F$, and the same cast skin may be distinguished in $G, H$, and $I$.

In stages $D, F$, and $I$, the covering may not be lifted without taking with it the insect itself. In the other stages represented, the covering may be lifted free from the insect.

$J$, The adult female as it occurs under the scale covering $I$. The threads represent the mouth parts, which are inserted into the plant. Their length may be twice the diameter of the adult insect.

$K$, The scale covering of the male. The same first cast skin may be noted. The cast skins from the other three molts of the male are not incorporated in the scale covering. The winged male emerges from beneath the narrower (lower) end of this eovering, at a time when the same-aged female is in stage $H$, or between stages $G$ and $H$.

The photograph was taken from a colored chart and the different shades are not correctly reproduced. On the original chart, $L$ represented the yellow scale. The yellow scale is similar in size to the red scale, but it is of a lighter color.

All of the figures are of the same relative size, with an enlargement of 20 diameters. (From Bulletin 542.)

determined. On the basis of counts made on control fruits the percentage of the insects that died from natural causes in the eighteen-day interim after the treatment was also determined. The results of the experiment are shown in table 5 . The mortality of both the adult and the immature scales would have been much greater if the counts had been made a month or six weeks after treatment. 
The ease with which scale in the immature stages may be killed with oil spray may be accounted for by the fact that, as compared with the adults, they are less firmly fixed to the surface upon which they rest and,

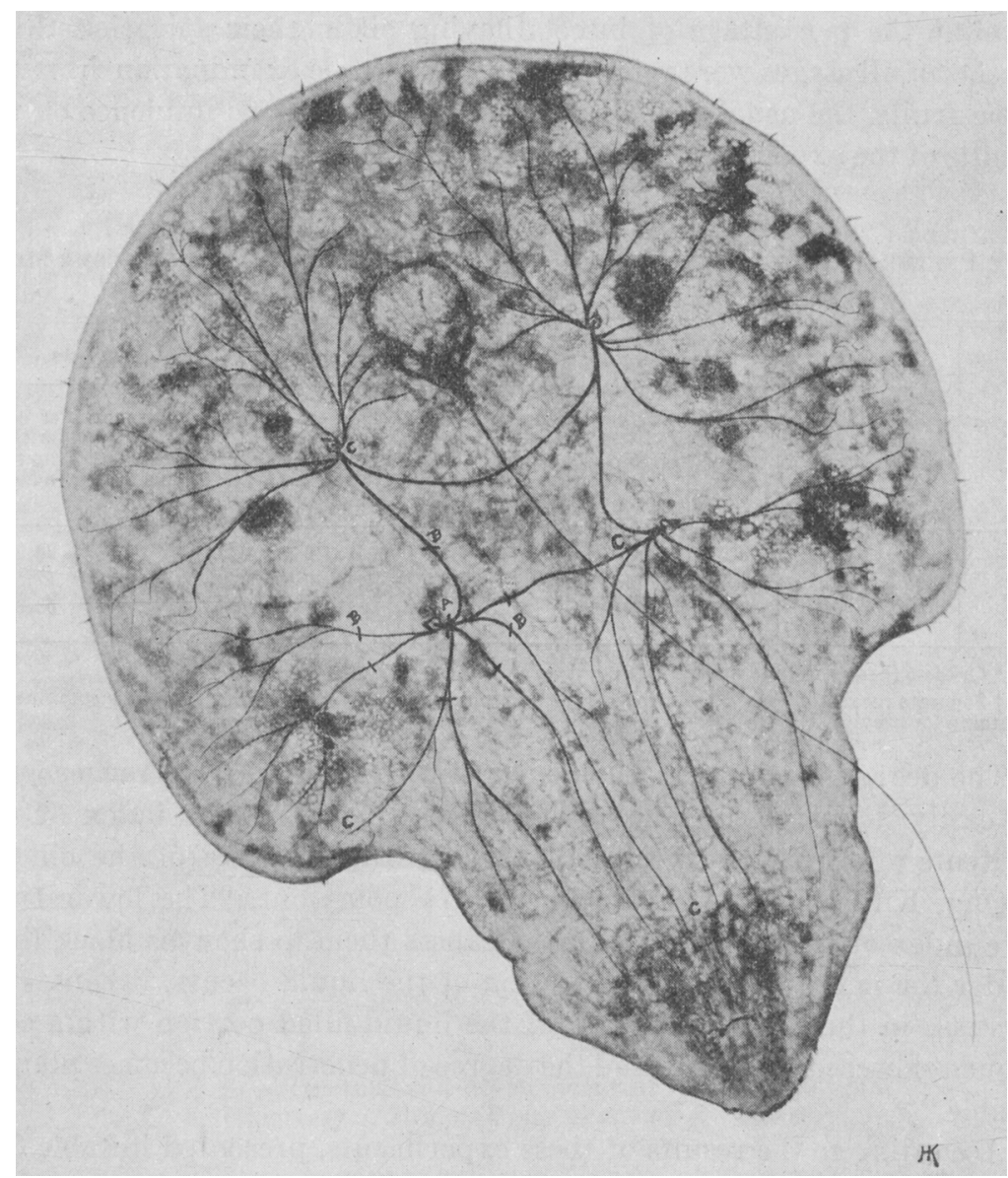

Fig. 4.-Ventral aspect of the California red scale, Aonidiella aurantii (Maskell), showing the tracheal system. (From Hilgardia Vol. 2, No. 9.)

except during molts, are free from their armors. Also the spiracles of the immature insects are at a lesser distance from the margins of their bodies than are those of the adult scale; consequently less oil is necessary on the surface in order that some may reach the spiracles. The respiratory system of the female red scale in the gray adult stage is shown in figure 4. In this stage the armor may be lifted from the insect, and it is then that the red scale is an excellent subject for microscopic examination. 
Penetration of Oil into the Spiracles.-An experiment was made in which lemons infested with red scale were sprayed with different concentrations of oil by means of a laboratory precision sprayer; the scales were examined at different intervals of time after the spraying to determine the percentage of insects having oil in their spiracles. Since insects of all stages were removed for microscopic examination from the same fruits, the usual variability in oil deposit had no influence on the results of the experiment.

\section{TABLE 6}

The Penetration of Oil into the Spiracles of Rep Scale in the Second-Molt, Gray-Adult, and Adult Stages on Lemon Fruits

\begin{tabular}{|c|c|c|c|c|c|c|c|c|c|c|}
\hline \multirow[b]{2}{*}{$\begin{array}{l}\text { Per cent } \\
\text { of oil* }\end{array}$} & \multirow[b]{2}{*}{$\begin{array}{l}\text { Hours } \\
\text { after } \\
\text { treat- } \\
\text { ment }\end{array}$} & \multicolumn{3}{|c|}{ Second-molt insects } & \multicolumn{3}{|c|}{ Gray-adult insects } & \multicolumn{3}{|c|}{ Adult insects } \\
\hline & & $\begin{array}{c}\text { Number } \\
\text { with } \\
\text { spir- } \\
\text { aclest } \\
\text { visible }\end{array}$ & $\begin{array}{c}\text { Number } \\
\text { with } \\
\text { spir- } \\
\text { acles } \\
\text { oily }\end{array}$ & $\begin{array}{l}\text { Per cent } \\
\text { with } \\
\text { spir- } \\
\text { acles } \\
\text { oily }\end{array}$ & $\begin{array}{c}\text { Number } \\
\text { with } \\
\text { spir- } \\
\text { aclest } \\
\text { visible }\end{array}$ & $\begin{array}{c}\text { Number } \\
\text { with } \\
\text { spir- } \\
\text { acles } \\
\text { oily }\end{array}$ & $\begin{array}{l}\text { Per cent } \\
\text { with } \\
\text { spir- } \\
\text { acles } \\
\text { oily }\end{array}$ & $\begin{array}{c}\text { Number } \\
\text { with } \\
\text { spir- } \\
\text { aclest } \\
\text { visible }\end{array}$ & $\begin{array}{c}\text { Number } \\
\text { with } \\
\text { spir- } \\
\text { acles } \\
\text { oily }\end{array}$ & $\begin{array}{l}\text { Per cent } \\
\text { with } \\
\text { spir- } \\
\text { acles } \\
\text { oily }\end{array}$ \\
\hline $2 / 3$ & 3 & 25 & 22 & 88.0 & 23 & 19 & 82.6 & 21 & 6 & 28.6 \\
\hline $2 / 3$ & 15 & 20 & 19 & 95.0 & 20 & 18 & 90.0 & 21 & 9 & 42.8 \\
\hline 1 & 16 & 25 & 25 & 100.0 & 25 & 25 & 100.0 & 36 & 23 & 63.9 \\
\hline
\end{tabular}

* Grade-5 (heavy) oil sprayed.

† Separate records were made for insects not having all four spiracles visible; these are combined in this table for brevity.

The degree to which oil has penetrated the spiracles or tracheae can be easily discerned because of the change in refractive index of the contents of the tracheal tubes caused by the entrance of the oil. As deOng, Knight, and Chamberlin (1927) point out, "The low refractive index of the air-filled tracheae causes them to show as black lines under the microscope. If penetration of the liquid occurs, it causes an increase in the refractive index of the liquid-filled portion with a consequent lowered visibility, and the degree of penetration becomes plainly visible."

According to the results of these experiments, presented in table 6, a given amount of oil is more apt to reach and penetrate the spiracles of insects in the second-molt or gray-adult stages than those in the adult stage. Of the insects with spiracles that were visible with the aid of a microscope, 64.3 per cent of the adults had no oil in the spiracles when sprayed with an oil spray of 2/3 of 1 per cent concentration; 36.1 per cent had no oil in the spiracles when sprayed with an oil spray of 1 per cent concentration. The corresponding figures for the gray adult were, respectively, 14.0 per cent and 0.0 per cent; and for the second molt, 8.9 per cent and 0.0 per cent. Likewise, the spiracles were not visible on a greater percentage of the adults than of the younger stages, prob- 
ably because no oil was present to make the wax covering the spiracles translucent. Only a small percentage of the spiracles of the adult insects are visible when the insects are not placed in a liquid capable of wetting the wax. The differences in the percentages of the spiracles reached by oil on the adults and on the younger insects are therefore actually greater than the data in table 6 indicate.

\section{EFFECT OF OIL SPRAY ON ADULT}

Structure of Adult.-As compared with the immature stages of the insect, the adult red scale is rather invulnerable to oil. This is because of the structure of the adult and the tenacity with which it adheres to the surface upon which it rests.

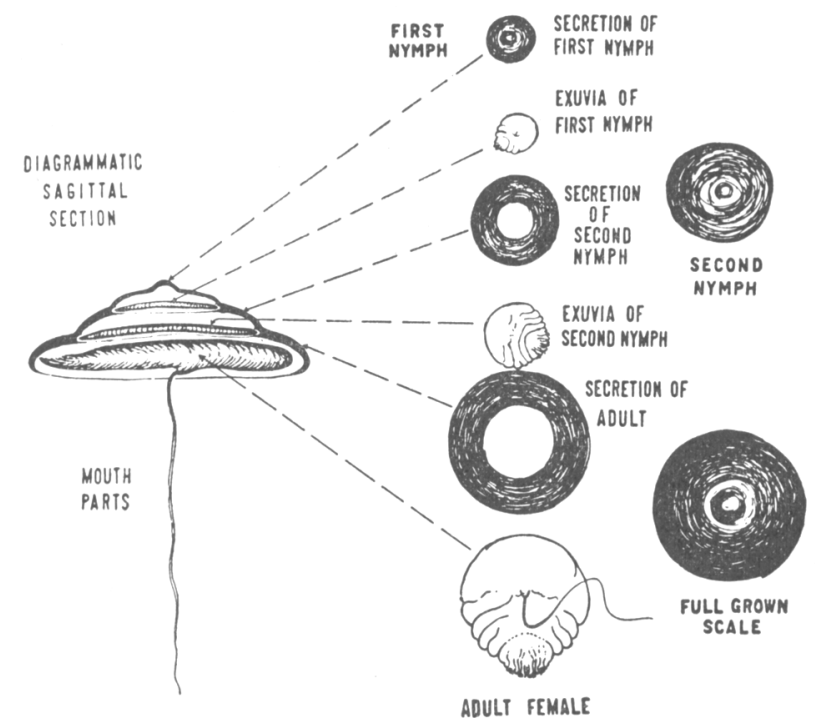

Fig. 5.-Structure and development of an armored scale. (Courtesy of Illinois State Academy of Science.)

According to Metcalf and Hockenyos (1930), the covering of the adult armored scale (fig. 5) consists of the secretion of the first-instar nymph and the skin shed by it, the secretion of the second-instar nymph and the skin shed by it, and the secretion of the adult female. In the case of the red scale, the ventral covering of the insect consists of the ventral cast skins or exuviae and a certain amount of wax. This covering is thin and pliable, however, compared with the hard, rigid dorsal armor of the insect (fig. 6).

The cross section of the insect (fig. 6) shows how well it is protected from insecticides by the unbroken covering extending both dorsally and 
ventrally over its soft body. The dorsal covering or "armor" is the thicker, measuring about $65 \mu$ in thickness, while the ventral covering measures about $20 \mu$. Both coverings appear solid and homogeneous in character under high magnification unless sections are cut very thin $(2 \mu)$, in which case it appears that the coverings are composed of laminae with spaces between them. These spaces are discernible whether the scale has been prepared and stained for sectioning in the usual manner or merely embalmed in paraffin and sectioned without preparation of any kind.

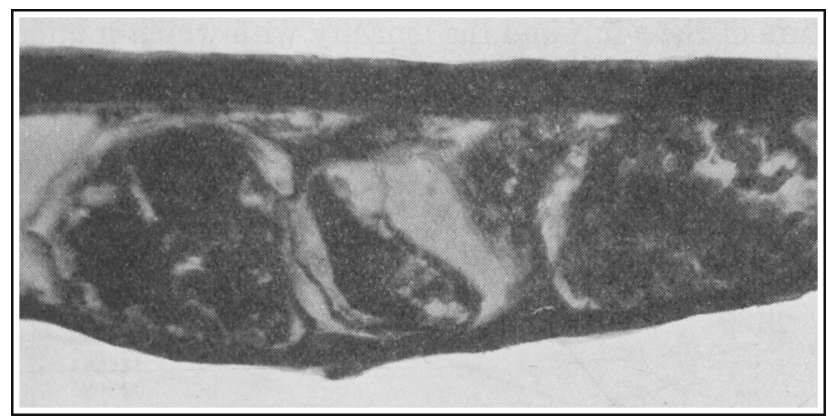

Fig. 6.-Median cross section of the California red scale showing difference in thickness of the dorsal and ventral coverings of the insect $(\times 145)$.

The thin wax margin of the insect which is extended beyond its body after the molting period is composed of loosely woven threads of the wax; sometimes these may be seen exuding from glands on the pygidia of insects between molts. The waxy margin is, of course, very readily penetrated by oil, and this may be one of the reasons why the insects, when they are expanding under the waxy covering, are very vulnerable to oil spray.

The shed skins are composed of chitin, while the secretions are wax and a nonwaxy substance, the exact chemical nature of which, as regards the armored scales, is not known (Metcalf and Hockenyos, 1930). However, a very complete analysis of the secretions of a number of unarmored scales has recently been made by Kono (1932-35). The dried Florida red scale, Chrysomphalus aonidum L., was found by Metcalf and Hockenyos (1930) to consist of between 31 and 34 per cent of wax when carbon tetrachloride was used as the wax solvent. Haas (1934), using an ether extraction method, extracted wax averaging 10.17 per cent of the body dry weight of California red scale. These insects were taken from areas where they are known to be resistant to hydrocyanic acid gas fumigation, while from scale taken from nonresistant areas he ex- 
tracted an average of 16.83 per cent of wax. The variation in the figures obtained by Metcalf and Hockenyos and by Haas on these closely related scales might be accounted for by the difference in the solvents used to extract the wax. Metcalf and Hockenyos (1930), after extracting 11 per cent of the total weight of oyster-shell scales with ether, extracted another 24 per cent with carbon tetrachloride. In the same paper these investigators state that the solubility of the wax of oyster-shell scales in grams per cubic centimeter at room temperature is 0.0008 gram with

\section{TABLE 7}

Differences in Mortality of Adult Red Scales with and without Their ARMORS LifTed ON ONE Side

\begin{tabular}{|c|c|c|c|c|c|c|c|c|}
\hline $\begin{array}{l}\text { Grade } \\
\text { of oil } \\
\text { used }^{*}\end{array}$ & $\begin{array}{c}\text { Date } \\
\text { sprayed } \\
(1933)\end{array}$ & $\underset{(1933)}{\text { Date }}$ & Treatment & $\begin{array}{c}\text { Total } \\
\text { sprayed }\end{array}$ & $\begin{array}{l}\text { Alive, } \\
\text { per cent }\end{array}$ & $\begin{array}{l}\text { Total } \\
\text { check }\end{array}$ & $\begin{array}{l}\text { Alive, } \\
\text { per cent }\end{array}$ & $\begin{array}{c}\text { Net } \\
\text { mortality, } \\
\text { per cent }\end{array}$ \\
\hline \multirow{2}{*}{3} & \multirow{2}{*}{ July 18} & \multirow{2}{*}{ Aug. $\overline{1} 1$} & Lifted & 1,470 & 2.8 & 1,099 & 64.8 & $95.7 \pm 0.44$ \\
\hline & & & Unlifted & 1,756 & 12.6 & 1,544 & 72.6 & $82.6 \pm 0.72$ \\
\hline \multirow{2}{*}{5} & \multirow{2}{*}{ Aug. 2} & \multirow{2}{*}{ Aug. 26} & Lifted & 368 & 10.8 & 266 & 71.0 & $84.8 \pm 1.50$ \\
\hline & & & Unlifted & 460 & 14.1 & 255 & 74.1 & $81.0 \pm 1.43$ \\
\hline \multirow{2}{*}{1} & \multirow{2}{*}{ Oct. 4} & \multirow{2}{*}{ Oct. 23} & Lifted & 3,562 & 19.7 & 2,138 & 79.6 & $75.3 \pm 0.55$ \\
\hline & & & Unlifted & 2,399 & 28.2 & 3,503 & 84.7 & $66.7 \pm 0.70$ \\
\hline \multirow{2}{*}{5} & \multirow{2}{*}{ Oct. 4} & \multirow{2}{*}{ Oct. 23} & Lifted & 2,078 & 10.4 & 2,138 & 79.6 & $86.9 \pm 0.58$ \\
\hline & & & Unlifted & 1,687 & 15.6 & 3,503 & 84.7 & $816 \pm 0.69$ \\
\hline
\end{tabular}

* Oil used at $11 / 2$ per cent concentration in each test.

$\dagger$ Net mortality and probable error computed as in table 5 .

carbon tetrachloride and 0.0084 gram with ether; hence, it would appear that ether is by far the better wax solvent and that extractions made with ether would be the more reliable. Carbon tetrachloride extracts a large number of organic compounds besides wax, and investigators generally have abandoned its use for the extraction of waxes and fats from organic material.

Penetration of Oil into the Spiracles.-It can be seen from table 6 that a much greater amount of oil is necessary to insure penetration into the spiracles of the adult scale insect than into those of the immature stages. As stated before, this is probably caused by the greater distance the oil must travel in order to reach the spiracles and the greater tenacity with which the adult insect is attached to its substratum. The adult, also, is supplied with a ventral covering, which probably aids in keeping oil away from the spiracles. This ventral covering is absent from immature insects between the molting periods.

If a sufficient amount of oil is deposited by the spray mixture, pene- 
tration to the spiracles may occur in less than a minute. Since oil penetrates into solid wax very slowly, as can be readily demonstrated, the oil apparently must reach the spiracles by passing between layers and particles of wax and other substances comprising the bulk of the material lying between the body of the scale and its substratum.

A slight lifting or loosening of the margin of the scale over half of its circumference by means of a scalpel causes the oil to reach the spiracles very readily and greatly increases the mortality resulting from a given amount of oil spray, as is shown in table 7 .

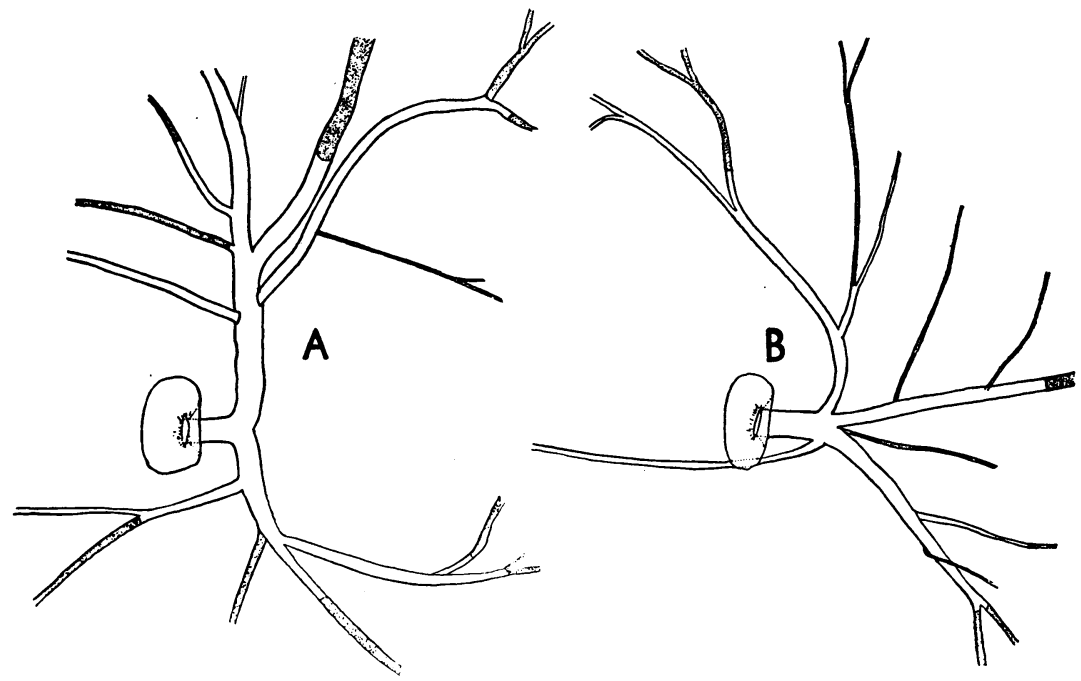

Fig. 7.-Main trunks of the tracheal system of the gray adult of the California red scale, showing the progress of oil into the tracheae. The stippled areas represent portions of the tracheae into which the oil has not yet penetrated. $A$, Left anterior spiracle; $B$, left posterior spiracle.

Tracheal Penetration.-Upon reaching the spiracles of a live insect, the oil immediately flows into the tracheae as if there existed no regulatory mechanism in the spiracle to exclude foreign matter even temporarily, although Nel (1933) suggests that ridge-like processes projecting into the lumen of the spiracle, together with certain muscles which he was able to observe, probably constitute a closing apparatus. The oil moves through the tracheae in a jerky manner, flowing rapidly for a distance, then ceasing movement for a short period. It may be that the periods between the movements of the oil indicate periods in which a certain amount of air already absorbed is being used by the insect. The air pressure within the trachea is thus gradually reduced until the inertia of the oil column is overcome by the capillary attraction of the oil to the wall of the trachea. There is a consequent sudden movement 
forward of the oil column until it is again stopped by the pressure of unused air within the trachea.

Sometimes the oil will not enter some branches of the tracheae, although it enters others immediately and may reach the extremities of the tracheoles in a short time (fig. 7). The pressure set up in the tracheae by the inflow of oil may disrupt the ends of the tracheal branches, causing a rapid flow of oil without resistance from the air in the lumen of the

TABLE 8

Results of Attempts to Suffocate Red Scale by Various Methods of Sealing WITH BALSAM AND PARAFFIN WAX

\begin{tabular}{|c|c|c|c|c|}
\hline \multirow[b]{2}{*}{ Treatment } & \multirow[b]{2}{*}{$\begin{array}{l}\text { Number of } \\
\text { insects } \\
\text { examined }\end{array}$} & \multicolumn{3}{|c|}{ Net per cent mortality } \\
\hline & & $\begin{array}{c}\text { Five } \\
\text { days after } \\
\text { treatment }\end{array}$ & $\begin{array}{c}\text { Sixteen } \\
\text { days after } \\
\text { treatment }\end{array}$ & $\begin{array}{l}\text { Thirty } \\
\text { days after } \\
\text { treatment }\end{array}$ \\
\hline Margin smeared with balsam. . & 178 & $\ldots$ & 23.4 & 18.6 \\
\hline $\begin{array}{l}\text { Margin smeared with balsam, armor } \\
\text { smeared with oil. ................. }\end{array}$ & 246 & 95.1 & 95.2 & 100.0 \\
\hline Armor smeared with balsam, margin & 173 & 132 & 60 & 103 \\
\hline $\begin{array}{l}\text { left free........... } \\
\text { Entire insect coverd with balsam. }\end{array}$ & 208 & $\begin{array}{ll}10.2 \\
51.8\end{array}$ & 93.8 & 94.0 \\
\hline Entire insect covered with paraffin.. & 180 & 73.0 & 82.9 & 100.0 \\
\hline
\end{tabular}

tracheae. Many insects having oil in their tracheae also have one or more sharply defined bloated areas, indicating the presence of liquid within the body.

With regard to insects situated on smooth surfaces, such as the fruit, leaves, and green bark, a sufficient amount of oil is usually deposited by spray mixtures of average concentration to insure the penetration of oil into the tracheae in a very large percentage of the insects. Obviously these insects are killed by suffocation. Some, however, receive oil in only one, or possibly in none of the four spiracles. In these cases the oil entering the single spiracle, or the oil present in the body of the insect, may ultimately cause the death of the insect, although not until several weeks after the death of insects which had all the spiracles blocked with oil.

One might argue that even if the oil does not actually penetrate beneath the insect and enter the spiracles it may still suffocate the insect by sealing the edges of the armor. Attempts were made to suffocate red scales on lemon fruits by smearing the margins of their armors with balsam, the armors being left uncovered. Only a small number of the insects were killed, and these may have been broken loose from the substratum on which they were resting and been killed in this manner. As can be seen from table 8 , the insect may obtain air either from beneath the margin of the armor or through the armor itself. That oil would 
suffocate the red scale by sealing the margins of the armor, is therefore improbable, especially since the oil is for the most part drawn into the substratum on which the insect rests. Such absorption takes place within a period ranging from a few hours to one or two days, according to the nature of the substratum. Even when the entire insect is covered with

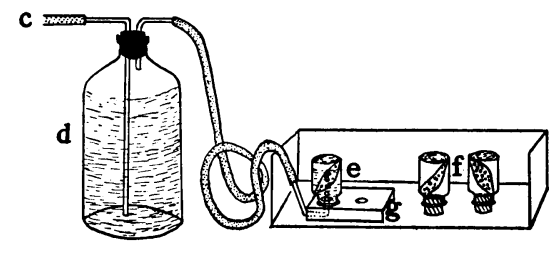

A
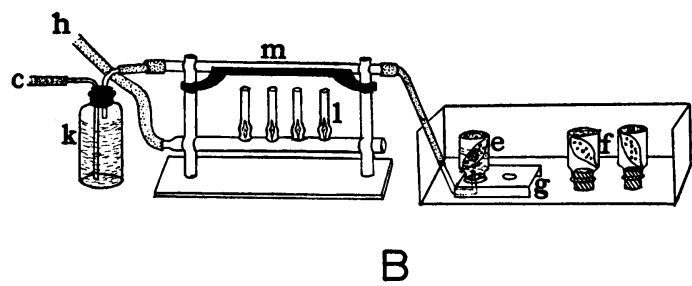

Fig. 8.--Experimental setup employed in removing oxygen from air and introducing the oxygenfree atmosphere in bottles containing red scale. $A$, Apparatus for pyrogallol method: $c$, tube leading to source of compressed air; $d$, bottle containing alkaline pyrogallol; $e$, bottle containing red scale on a lemon peel and water (the bottle is also immersed in water to above the neck) ; $f$, bottles having had the water within displaced by oxygen-free atmosphere; $g$, stand supporting bottle $e$. B, Apparatus for hot-copper method: $h$, tube leading to gas supply; $k$, bottle of concentrated sulfuric acid; $l$, gas burner; $m$, Pyrex tube containing copper turnings; others as in $A$.

balsam or paraffin, the percentage of mortality is not great for several weeks after treatment, the seal in this case probably being not entirely impervious to oxygen.

Oxygen Requirements of the Red Scale.-In view of the apparently small amounts of oxygen required by the red scale, it was considered advisable to determine how long the insect can live in an atmosphere as nearly as possible devoid of oxygen. Two methods were employed in freeing air of oxygen. Both are illustrated in figure 8. According to method A, air is slowly passed through alkaline pyrogallol prepared by combining 1 volume of 22 per cent pyrogallol with 6 volumes of 60 per cent potassium hydroxide. According to method B, air is slowly passed through concentrated sulfuric acid for dehydration, then over hot 
copper turnings tightly packed in a Pyrex tube. In either case the air from which the oxygen has been removed is bubbled into wide-mouthed 8-ounce bottles (fig. 8, $c$ ) in which have been placed freshly cut lemon peelings heavily infested with red scale. The confinement of the scales in the bottles causes in itself no appreciable mortality. In these bottles the oxygen-free atmosphere displaces freshly boiled and cooled water.

When the bottles are full of the oxygen-free atmosphere, they are stoppered under water and left standing in water well over the neck of the bottle until the examination of the insects is made. In one instance red scales in bottles with oxygen-free atmosphere left standing in water without being stoppered were alive four days after treatment; others, in bottles of oxygen-free atmosphere that had been stoppered, were all dead. In the case of the insects in the unstoppered bottles, it may be supposed that enough oxygen passed off from the water to satisfy the oxygen requirements of the insects.

When ready for examination, the insects are placed on a microscope slide with their venters upward. They are then covered with oil to make the wax on their bodies translucent. They are examined with the low power of the microscope for movements of the pygidium or the pharyngeal muscles; these muscles are located ventrally slightly anterior to the center of the body in the female insect. If the insects are alive, some movement can be seen in either or both of these regions of the body. If no movement can be discerned after a few minutes of examination, the insects are considered dead. In the writer's experience, red scales showing no movement are invariably proved to be dead by the appearance of their body fluids a few days later. The absence of movement in the pygidium and the pharyngeal muscles can therefore be employed as an accurate criterion of death. If no movement is found in the pharyngeal muscles, however, the pygidium should be watched carefully for a few minutes, for movements of the pygidium may sometimes be discerned several days after the pharyngeal muscles have ceased moving. Sometimes the movements of the pygidium are so feeble that only one having experience as to the nature of such movements, and hours of practice, can discern them.

The mortality effected by the absence of oxygen in the atmosphere is shown in figure 9. Each of the points in figure 9 was determined on a basis of 20 insects examined. The hot-copper method is obviously the more efficient for removing oxygen from air. When a burning match is inserted in a bottle of oxygen-free atmosphere prepared by method B (fig. 8), the flame is instantly extinguished. The flame is not so quickly extinguished by the atmosphere prepared by method A. Method A might be more efficient if the alkaline pyrogallol were continually stirred dur- 
ing the course of the experiment in order to present a constantly new surface of the reducing agent to the air being bubbled through the liquid.

The experiment was repeated according to method B, but with leaves of the carob tree, Ceratonia siliqua, heavily infested with red scale, instead of infested lemon peels. Forty-eight hours after treatment, 486 treated insects were examined and none were found to be alive according to the criteria established for determination of live and dead insects in

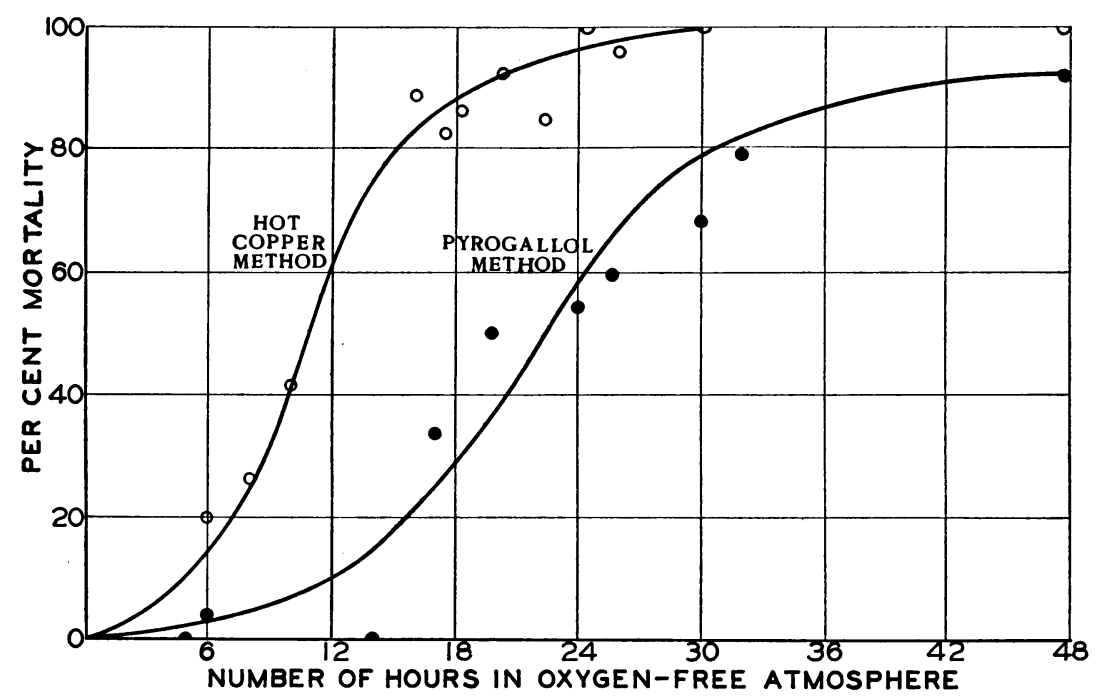

Fig. 9.-Net mortality of red scale confined in oxygen-free atmosphere.

the present series of investigations. According to the same criteria 262 insects out of 300 examined were found to be alive in the check lots; these insects had been kept in bottles from which water had been displaced by air instead of by oxygen-free atmosphere as in the treated lots.

Red scale kept in a fumigator in which a vacuum ranging from $261 / 2$ to $271 / 2 \mathrm{~mm}$ of mercury was maintained for 9 hours were alive at the end of this period. A more complete vacuum could not be maintained with the equipment employed in this test.

Red scales on an infested lemon were placed in a quart jar of water for 10 days ; 17 out of 20 adult scales examined with a microscope showed perceptible movements of the pygidium at the end of this period, probably having obtained sufficient oxygen from the water in which they were submerged.

Lemons infested with red scale were immersed in a grade- 5 oil, then removed from the oil, and determinations made periodically of the percentage of live insects. The last live insects were found 72 hours after 
the infested fruit had been immersed in oil. Carob leaves infested with red scales were immersed in grade- 5 oil and a certain number of the scales were removed and examined periodically as before. Several live insects were found 60 hours after immersion, but none 72 hours after immersion. Over a thousand insects were examined in each of the above experiments.

In view of the fact that oil is practically devoid of oxygen, the greater period of survival of red scale in oil than in oxygen-free atmosphere may seem at first thought anomalous. However, deOng, Knight, and Chamberlin (1927) found that the same situation obtained with regard to the mealybug Phenacoccus colemani Ehr. These investigators found that the average period of lethal immersion in oil for mealybugs was nearly 7 days, while the average period of lethal immersion in hydrogen was 64 hours, or approximately $21 / 2$ days. It may be that when insects are immersed in oil, the air in their bodies and that adhering to the surface of their bodies is kept from leaving and becomes a source of oxygen for the insects for a certain period. This would be especially true of the mealybug with its waxy filaments on the body surface. If insects are immersed in an oxygen-free atmosphere, however, the air in and about their bodies becomes dissipated into the atmosphere and is then probably too dilute for their use.

Penetration of Oil through Armor.-Oil readily penetrates the armor of a scale insect. This may be demonstrated by removing a live adult insect, carefully scraping the body away from the armor, turning the armor with concave side upward, and placing a small amount of oil on the concavity of the armor by means of a camel's-hair brush. Sometimes the oil will penetrate through the armor in a few minutes and, with the aid of a binocular and proper lighting, may be discerned on the dorsal side of the insect. If the scales are treated as described above and placed on a microscope slide and left overnight, the oil placed in the concavities of the armors will be found in pools beneath the armors the next morning.

In order to determine whether the penetration of oil through the armor of the red scale, unaccompanied by tracheal penetration, will result fatally to the insect, small amounts of a grade-5 oil were placed on the apexes of the armors of a large number of insects by means of a camel's-hair brush. A sufficient amount of oil was usually present to spread over the dorsal surface of the armor, but not enough to penetrate under the body of the scale and enter its spiracles. This could be determined by removing the insect and noting whether or not the wax was oil-soaked under its body (fig. 10).

The treated scales were infesting mature lemons. In the present experiment a half of each lemon was marked off.with ink and the scales on 
this half were treated with oil, while those on the other half were left untreated as chẹcks. The following day the experiment was repeated. Altogether 5,817 insects on 54 lemons were treated, a similar number of insects being left untreated as checks.

Four days after the scales were treated in the preceding manner, some were placed under the low power of a compound microscope and

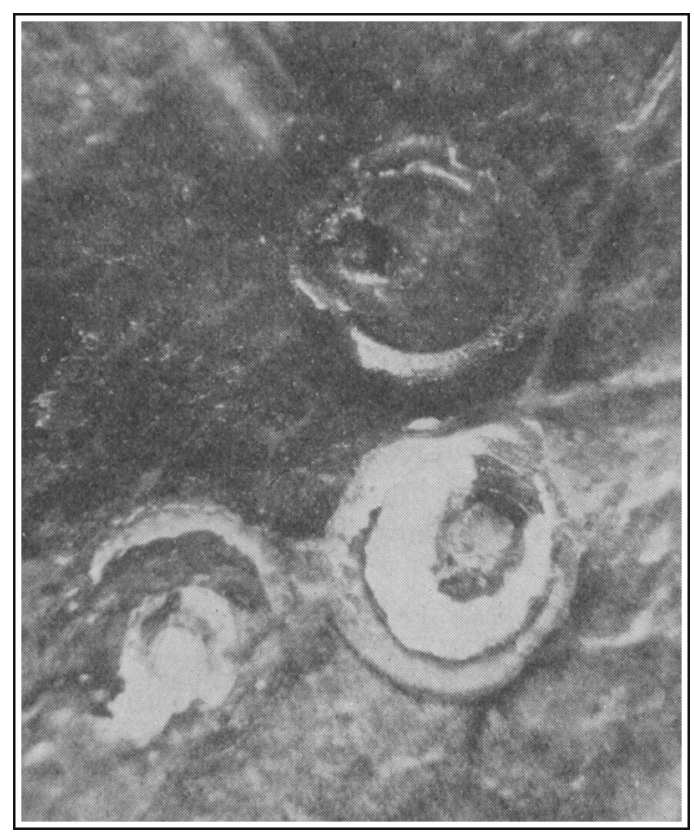

Fig. 10.-Adult red scales broken loose from their places of attachment and turned to the right. Note difference in appearance of place of attachment and the ventral surface of the insect between scale sprayed with oil (above) and untreated scale (below). $(\times 18)$.

those showing signs of life were examined for the symptoms of a sublethal dosage of oil from the usual oil spray. The grouping of dead embryos under the armors of the adults at the bases of the pygidia was frequently observed. Thirteen days after treatment a large percentage of the live insects were giving birth to dead embryos, some of them apparently without appendages.

Of 25 treated insects examined 15 days after treatment, 8 had no crawlers under them and the remaining 17 had a total of 20 live and 87 dead crawlers, the number per insect varying from 1 to 5 live and 2 to 12 dead crawlers. Of the 25 untreated insects, 15 had no crawlers and 10 
had a total of 15 live crawlers; the number per insect never exceeded 2. No dead crawlers were found under the untreated scales.

The large number of live crawlers grouped beneath the armors of treated scales indicates that the waxy margin of the scale may in some cases have been softened by the oil and may have sealed the crawlers beneath the armor, from which they could not escape.

Fifteen and 44 days after treatment the scales were examined to determine the percentage that survived the treatment of oil applied to their armors. Including the insects in the checks, a total of 4,344 were examined in this experiment. Of those examined 15 days after treatment, $5.6 \pm 0.73$ per cent were already dead; and of those examined 44 days after treatment $17.7 \pm 3.31$ per cent were dead. The data show that probably only a small percentage, if any, of adult red scales are killed by penetration of oil through their armors. The insects receiving enough oil on the armor to result in death are usually killed by tracheal penetration, for if more oil is placed on the armor of the scale than in the present experiment, the oil will creep off the armor and under the body of the insect and enter the spiracles. It is possible, however, that some of the insects-those that linger for a month or more after treatment before dying-may have no oil in their tracheae, but die as the result of oil penetration through the armor. If the margins of the scales are sealed with balsam so that a large amount of oil may be placed on the insects' armors without creeping under their bodies, the oil will always result in the death of the insects (see table 8).

Effect of Sublethal Dosages of Oil on Reproduction.-Insects that receive oil in insufficient amounts for immediate death will continue to give birth to young until they die, whether the death is attributable to the oil or to natural causes. Since the final effect of an oil spray treatment on a red-scale population must depend to some extent on its effect on the reproductive capacity of the insects not killed outright by the spray treatment, studies were made of the difference in the production of crawlers by live, untreated insects and live insects treated with oil spray. Whether the insects were alive or dead was determined by the presence or absence of movement in the pygidium or the muscles governing the pharyngeal sucking and salivary apparatus.

Some lemons infested with red scale were sprayed with grade-1 (light) oil at 2 per cent, November 16, 1933. Treated and untreated insects were examined November 29, 1933. Of 50 treated insects examined, 27 had no crawlers under them and the remaining 23 had a total of 8 live and 101 dead crawlers, the number per insect varying from 1 to 17 . Of 50 untreated insects, 36 had no crawlers, 13 had a total of 19 live crawlers, and 1 had a single dead crawler. 
Normally only 1 or 2 crawlers, if any, are grouped at any one time around the pygidium under the armor of the adult female. These make a rapid exit under the waxy margin of the parent and leave room for the emergence of other crawlers. However, in the case of live insects which have received a sublethal dosage of spray, a large percentage of the young are born dead (fig. 11). Many of the dead embryos found clus-

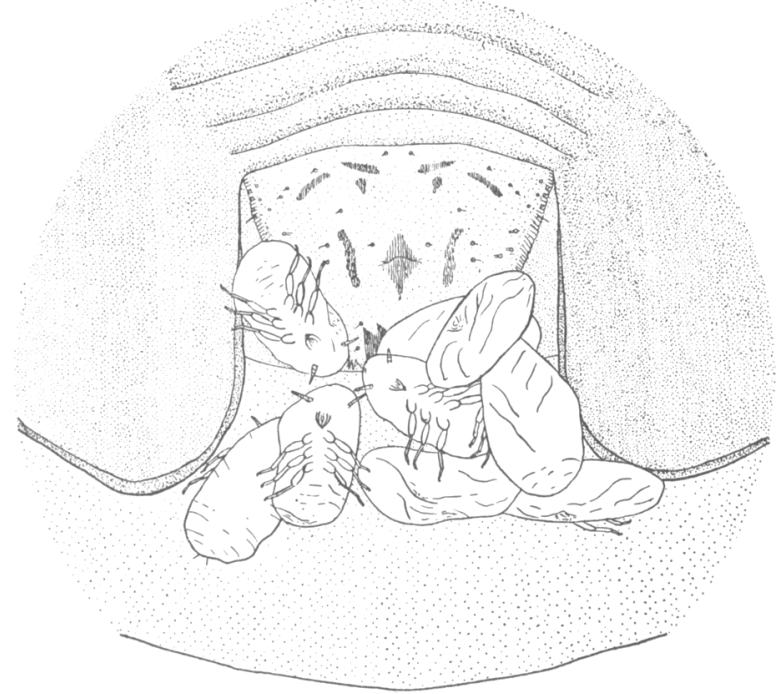

Fig. 11.-Ventral aspect of the posterior portion of a red scale which has received a sublethal dosage of oil spray. Note group of dead crawlers in the region of the pygidium.

tered about the pygidium in these cases are premature, sometimes having developed not even slight vestiges of the usual appendages. Occasionally a live crawler may be seen among the dead embryos, its exit possibly being closed by the mass of dead individuals it encounters in its path upon emergence. The writer has found as many as eighteen live crawlers under the armors of normal live insects, the posterior margins of which had been sealed with balsam. Among the insects with their entire margins sealed with balsam, which were examined 16 days after treatment (see table 8), there were an average of 4.2 live and 0.6 dead crawlers under the armor of each live adult insect.

The preponderance of dead over live crawlers in the case of the progeny of the live, treated insects does not indicate the true ratio; for the live insects probably for the most part crawl away from the body of the adult scale in the usual manner. The dead crawlers, of course, remain where born, and accumulate in considerable numbers. However, the fact 
that only 8 live crawlers were found, as compared with 19 in the case of the untreated insects, indicates that a sublethal dosage of oil spray may have some value in reducing a red-scale population.

Scales on Rough Bark.- It is on the rough bark that the greatest percentage of insects succumb to oil sprays without actual tracheal penetration of oil. In one instance 1,000 adult scales were removed from the branches of lemon trees 24 hours after the trees had been sprayed with grade- 5 oil at $12 / 3$ per cent concentration, and determinations were made as to whether or not the oil had penetrated under the bodies of the insects. The insects examined showed by their appearance that they had been alive before the spray was applied. As stated before, the presence or absence of oil can be determined by the appearance of the wax on the insects' bodies or the wax left on the tree when the insects are removed. It was found that 52.4 per cent of the insects had oil beneath their bodies and, presumably, in their tracheae. Counts made six weeks later showed a net mortality from the spray of 86.3 per cent; this indicates that 33.9 per cent of the insects were killed without tracheal penetration.

The ease with which insects are killed on the bark without tracheal penetration is to be expected in view of the probability that on the bark they are less vigorous than on other parts of the tree, as shown by their greater susceptibility to hydrocyanic acid gas and their smaller size and less vigorous appearance. On the bark, however, the least oil is available for penetration under the insect body, for it is rapidly absorbed by the dead outer layer of the bark. Consequently, despite the lower vitality of the scales living on the bark, a greater percentage survive oil-spray treatment on that part of the tree than on the green twigs, leaves, and fruit, where penetration of oil into the substratum upon which the insects live is less rapid.

Actual counts of 21,965 insects showed a survival of 17.35 per cent of the red scale on the bark, 1.36 per cent on the green twigs, 0.67 per cent on the leaves, and 7.03 per cent on the fruit of lemons sprayed with 2 per cent grade-5 oil (Ebeling, 1931). In other experiments involving the counting of 404,772 red scale, 18.20 per cent of the insects survived grade-5 oil sprays at $12 / 3$ per cent concentration on the branches and 5.51 per cent survived on the fruit. Similar ratios existed with oil sprays at other concentrations (Ebeling, 1932).

The fact that oil sprays are not able to control red scale in case of heavy infestations appears to be largely due to the rapid absorption of the oil by the rough bark, and perhaps also to the effect of the nature of the bark surface on oil deposition. On other parts of the tree the control effected by the oil sprays is satisfactory at concentrations of spray safe for use on citrus trees. 


\section{POSSIBLE METHODS OF CONTROL}

If we may judge by analogy with other insects, an understanding of the relative susceptibility of the various stages of the red scale to oil spray should form a basis for practical control measures directed against this insect. Although the several generations of red scale occurring throughout the year overlap considerably in their various stages, yet a single spray of low concentration directed against the immature stages is sufficient to even up the life stages to a large extent. It may be possible to deal with the subsequent population of scale in accordance with the principles indicated in the present paper. Experiments are being made with this possibility in view.

The addition of substances to the oil spray which would retard the penetration of oil into the bark might increase its effectiveness against the scale without increasing injury to the tree. Experiments are being made with substances which, when added to the oil spray, are expected to act as physical barriers to the penetration of oil by clogging the pores of the bark. The ideal substance for use in this connection would be one which would not be absorbed by the bark and yet could be made into a quick-breaking emulsion of high depositing qualities. Paraffin wax has been found to meet these requirements satisfactorily. Laboratory and field experiments made to date have yielded promising results and warrant a thorough study of the possibilities of this type of treatment.

The wax has been emulsified with triethanolamine stearate or triethanolamine oleate and added to the oil spray separately or combined with oil in a single emulsion. In either case small amounts of emulsified paraffin have not only greatly increased the amount of oil deposited by an oil spray, and resulted in a more uniform distribution of the oil over the leaf surface, but have also increased the insecticidal efficiency of any given amount of oil deposited.

\section{SUMMARY}

The frequent instances of delayed lethal effect of oil have been ascribed by Smith (1932) to a "prolonged impairment of physiological processes such as might be induced by the presence of oil in the scale covering or in contact with the derm of the insect's body."

Preliminary observation had indicated that the ultimate effect of oil spray on a red-scale population is also influenced by the inhibition of the settling of crawlers for some time after the oil spray is applied. Experimental data presented in the present paper confirm this observation. They indicate that where the normal amount of oil is deposited in the 
application of oil spray under orchard conditions, there is a great reduction, for at least a month after the spray is applied, in the percentage of crawlers able to settle on the foliage. Among the crawlers able to settle and form whitecaps during this interim, there is a greater mortality than where oil spray has not been applied.

Attempts at control of the red scale with dusts directed against the crawlers have been unsuccessful because of practical considerations.

All immature stages of the red scale are more easily killed by oil spray than the mature adult, probably because they are not as thoroughly sealed to the substratum upon which they rest and because their spiracles are not as far from their margins ; they are thus more accessible to the oil.

The majority of adult scales are killed by tracheal penetration of the oil, although, at least on the bark, a large percentage of them die from an oil-spray treatment without tracheal penetration.

Adult red scales with their margins loosened or lifted from their substratum are more vulnerable to oil sprays than are those not treated in this manner.

It has been demonstrated that oil penetrates through the armor of the red scale.

The armors of adult scales were painted with oil, care being taken that no oil should enter beneath the bodies of the insects. In two experiments, 5.64 per cent and 17.78 per cent of the insects treated in this manner were killed by the treatment in 16 days and 44 days respectively. Those alive at the end of two weeks gave birth to a certain percentage of dead embryos and dead crawlers, as is typical of insects surviving the usual spray treatment.

Red scale were found to live in an oxygen-free atmosphere for as long as 26 hours. Immersed in oil, however, they were found to live as long as 72 hours.

A certain percentage of the progeny of adult scales receiving a sublethal dosage of oil spray die before they are born; some of these are born before they have developed the usual insectan appendages.

Because of the absorption of oil by the rough bark, and possibly also because of a lighter deposit of oil caused by the nature of the surface of the bark on the larger branches of citrus trees, it is on these parts of the trees that the greatest difficulty is experienced in the control of scale insects. 


\section{ACKNOWLEDGMENTS}

The writer wishes especially to express his sincere gratitude to Dr. R. H. Smith for aid and encouragement in the experimental work dealt with in the present paper and for a critical review of the manuscript. Many observations and experiments cited in this paper have been independently made by Dr. Smith, and he has also aided the writer materially by checking results and correcting certain misconceptions. Professors H. J. Quayle and W. M. Hoskins have reviewed the manuseript and offered valuable suggestions. Dr. H. B. Frost has aided in the proper interpretation of certain data, and Dr. H. D. Chapman suggested the laboratory set-up for the oxygen-deprivation experiments. 


\section{LITERATURE CITED}

DeONG, E. R., H. KNight, and J. C. ChamberLin.

1927. A preliminary study of petroleum oil as an insecticide for citrus trees. Hilgardia 2(9):351-384.

Ebeling, W.

1931. Method for determination of the efficiency of sprays and HCN gas used in the control of the red scale. California State Dept. Agr. Mo. Bul. 20:669-672. 1932. Experiments with oil sprays used in the control of the California red scale Chrysomphalus aurantii (Mask.) (Homoptera: Coccidae) on lemons. Jour. Econ. Ent. 25:1007-1012.

HAAS, A. R. C.

1934. Relation between the chemical composition of citrus scale insects and their resistance to hydrocyanic acid fumigation. Jour. Agr. Research 49:477-492.

Kono, M.

1932-35. Chemical studies on coccids produced in Japan. Jour. Agr. Chem. Soc. Japan 8:1150-60; 9:458-66, 467-74, 775-82, 1276-83; 10:360-67, 1228-35; 11:21-28, 647-58. Abstracted in: Chem. Abstr. 27:1409, 4312; 28:2418, $5538 ; 29: 1168,3045,6958$.

MetCalf, C. L., and G. S. Hockenyos.

1930. The nature and formation of seale insect shells. Illinois State Acad. Sci. Trans. 22:166-184.

NEL, R. G.

1933. A comparison of Aonidiella aurantii and Aonidiella citrina, including a study of the internal anatomy of the latter. Hilgardia 7(11):417-466.

SмIтн, R. H.

1932. Experiments with toxic substances in highly refined spray oils. Jour. Econ. Ent. 5:988-990.

1933. The tank-mixture method of using oil spray. California Agr. Exp. Sta. Bul. $527: 1-86$.

WOGLUM, R. S.

1926. The use of oil spray on citrus trees. [Abstract.] Jour. Econ. Ent. 19:732-733.

Woglum, R. S., and J. R. LA Follette.

1934. The double treatment for scale pests in California citrus orchards. Jour. Econ. Ent. 27:978-980. 